\title{
Upaya Guru BK dalam Mengembangkan Adversity Quotient Pada Siswa SMAN 1 Manyak Payed
}

\author{
Muliani ${ }^{1}$, Mawardi Siregar ${ }^{2}$, Rizky Andana Pohan ${ }^{3}$ \\ ${ }^{1}$ Bimbingan dan Konseling Islam, IAIN Langsa ${ }^{2}$ Bimbingan dan Konseling Islam, IAIN Langsa \\ ${ }^{3}$ Bimbingan dan Konseling Islam, IAIN Langsa \\ ${ }^{1}$ muliani@gmail.com
}

$\begin{array}{ccc}\text { First received: } & \text { Revised: } & \text { Final Accepted: } \\ \text { 01 January } 2019 & \text { 02 February } 2019 & \text { 04 March } 2019\end{array}$

\begin{abstract}
This study aims to describe the adversity quotient of SMAN 1 Manyak Payed students and the efforts of the BK teacher in developing adversity quotient in students. The research method used in this study is a qualitative type with a descriptive approach. Data were collected using observation, interview and documentation techniques. Determination of research subjects or informants in this study was done by purposive sampling. Data were analyzed using the Miles and Hubermen technique. The results showed that (1) the description of adversity quotient in SMAN 1 Manyak Payed students can be seen from all four dimensions, namely a) Dimension of control, students cannot control themselves when facing a problem. b) The dimension of ownership (recognition), students can admit mistakes made by apologizing and promising not to repeat the same mistakes again. c) The reach dimension (achievement), some students have the ability to limit difficulties so that they do not enter into other lives and some students have not been able to limit it. d) The dimension of endurance students assume every problem they face requires a long time in solving it. (2) the efforts of BK teachers in developing adversity quotient in SMAN 1 Manyak Payed students in the form of classical guidance and individual counseling services, where classical guidance is used first, if there is no change, then individual counseling and forms of collaboration between BK teachers and teachers will be conducted Students and parents to support the process of solving students' difficulties
\end{abstract}

Keywords: Efforts, Teacher School Counselor, Development, Adversity Quotient.

\begin{abstract}
Abstrak
Penelitian ini bertujuan untuk mendeskripsikan adversity quotient pada siswa SMAN 1 Manyak Payed dan upaya guru BK dalam mengembangkan adversity quotient pada siswa. Metode penelitian berjenis kualitatif. Data dikumpulkan dengan menggunakan teknik observasi, wawancara dan dokumentasi. Penentuan subjek penelitian atau informan dalam penelitian ini dilakukan dengan cara purposive sampling. Data di analisis dengan menggunakan teknik Miles and Hubermen, Hasil penelitian menunjukkan bahwa (1) gambaran adversity quotient pada siswa SMAN 1 Manyak Payed dapat terlihat dari keempat dimensi, yaitu a) Dimensi control (kendali), siswa belum dapat mengendalikan diri ketika sedang menghadapi suatu masalah. b) Dimensi ownership (pengakuan), siswa dapat mengakui kesalahan yang dilakukannya dengan meminta maaf dan berjanji tidak akan mengulangi kesalahan yang sama lagi. c) Dimensi reach (ketercapaian), sebagian siswa memiliki kemampuan dalam membatasi kesulitan agar tidak masuk ke dalam kehidupan lainnya dan sebagian siswa belum mampu membatasinya. d) Dimensi endurance (daya tahan) siswa menganggap setiap masalah yang di hadapinya memerlukan waktu yang lama dalam menyelesaikannya. (2) upaya guru BK dalam mengembangkan adversity quotient pada siswa SMAN 1 Manyak Payed berupa layanan bimbingan klasikal dan konseling individual, di mana bimbingan klasikal yang digunakan terlebih dahulu, jika tidak ada perubahan, maka akan dilakukan konseling individual dan bentuk kerjasama guru BK dengan guru Mapel dan orang tua siswa untuk mendukung proses menyelesaikan kesulitan siswa.
\end{abstract}

Kata Kunci: Upaya, Guru BK, Mengembangkan, Adversity Quotient. 


\section{PENDAHULUAN}

Wacana pendidikan, tidak mungkin tercapai tanpa performansi peserta didiknya yang produktif dan berprestasi, tetapi yang paling penting dalam konsep Pendidikan Anak Berbakat (PAB) selain IQ (Intelegene Quotient), EQ (Emosional Quotient), SQ (Spiritual Quotient), ada lagi AQ (Adversity Quotient), Adversity Quotient merupakan bentuk kecerdasan yang melatar belakangi kesuksesan seseorang, dimana orang yang memiliki $A Q$, mereka tidak mudah menyerah dan mempunyai semangat tinggi untuk mencapai tujuan.

Stoltz memperkenalkan konsep adversity quotient untuk menggambarkan daya juang yang dimiliki oleh seseorang. Adversity quotient menggambarkan pola seseorang dalam mengolah tanggapan atas semua bentuk kesulitan, baik dari kesulitan besar sampai gangguan terkecil. ${ }^{1}$ Adversity quotient memberitahu seberapa jauh seseorang mampu menghadapi dan mengatasi kesulitannya, meramalkan siapa yang mampu mengatasi kesulitan dan siapa yang akan hancur, meramalkan siapa yang akan melampauhi harapan atas kinerja dan potensinya serta siapa yang akan gagal, dan juga meramalkan siapa yang akan menyerah dan siapa yang akan gagal. $^{2}$

Stoltz mengelompokkan individu menjadi tiga, yaitu quitter, camper, dan climber. Penggunaan istilah ini diadaptasi dari kisah para pendaki gunung yang

1 Paul G. Stoltz, Adversity Quotient in A Work: Mengatasi Kesulitan di Tempat Kerja, Terjemahan oleh Alexander Sindoro (Jakarta: Interaksara, 2003), h. 28.

2 Paul G. Stoltz, Adversity Quotient: Mengubah Hambatan menjadi Peluang, Terjemahan oleh T, Hermaya (Jakarta: Gramedia Widia Sarana Indonesia, 2000), h. 8. hendak menaklukan puncak Everest. Adversity quotient inilah yang membedakan respon seseorang terhadap kesulitan atau tantangan. Ketika seseorang dihadapkan pada situasi yang semakin sulit, quitters akan menyerah, campers akan berkemah, sementara climbers akan bertahan dan tetap berusaha untuk mencapai kesuksesan. ${ }^{3}$

Adversity Quotient memiliki empat dimensi pembentuk. Berikut ini keempat dimensi yang merupakan dasar penentu adversity quotient individu, yaitu (1) Control (Kendali), menggambarkan sejauh mana seseorang mampu untuk secara positif mempengaruhi situasi serta sejauh mana seseorang dapat mengendalikan tanggapan dirinya sendiri terhadap suatu situasi (pengendalian tanggapan); (2) Ownership (Pengakuan), menggambarkan sejauh mana seseorang bertanggungjawab untuk memperbaiki situasi yang dihadapinya, tanpa mempedulikan penyebabnya; (3) Reach (Ketercapaian), menggambarkan sejauh manakah seseorang membiarkan kesulitan masuk ke dalam bidang kerja dan kehidupannya yang lain; dan (4) Endurance (daya tahan), menggambarkan seberapa lama seseorang menganggap kesulitan akan berlangsung. ${ }^{4}$

Bimbingan adalah suatu istilah yang luas dan biasanya dipakai dalam program umum sekolah. Pelayanannya ditujukan demi membantu para siswa untuk menyusun dan melaksanakan rencananya dan mencapai penyesuaian yang memuaskan dalam kehidupannya. Konseling biasanya dilihat sebagai bagian dari program pelayanan bimbingan yang ditujukan kepada siswa yang mempunyai

\footnotetext{
${ }^{3}$ Ibid, h. 18-19.

${ }^{4}$ Ibid, h. 141-162.
} 
masalah pribadi dan mereka tidak mampu memecahkannya sendiri.

Bimbingan konseling dapat dimaknai sebagai upaya pengembangan seluruh aspek kepribadian siswa, pencegahan terhadap timbulnya masalah yang akan menghambat perkembangan dan penyelesaian masalah yang dihadapinya, baik sekarang maupun yang akan datang. Pemberian bimbingan dan konseling harus diintensifkan baik di lingkungan sistem sekolah maupun di luar sekolah.

Ada fenomena sejumlah siswa yang jelas-jelas cerdas atau berbakat tetapi gagal membuktikan potensi dirinya. Ada pula siswa yang memiliki IQ yang tinggi tetapi gagal dalam meraih prestasi belajarnya. Sebaliknya tidak sedikit orang yang memiliki IQ tidak tinggi tetapi justru lebih unggul dalam prestasi belajar. Pada umumnya ketika individu dihadapkan pada kesulitan dan tantangan hidup kebanyakan individu menjadi loyo dan tidak berdaya. Mereka berhenti berusaha sebelum tenaga dan kemampuannya benar-benar teruji. Banyak orang yang mudah menyerah sebelum berperang. Mereka inilah yang dimaksudkan dengan rendah Adversity Quotient-nya.

Sesuai dengan pengamatan penulis terdapat gejala-gejala siswa SMAN 1 Manyak Payed yang mempunyai adversity quotient yang rendah. Dalam prestasinya kebanyakan siswa yang tidak optimal dalam proses belajarnya, sebab terdapat anak yang membolos pada waktu jam pelajaran, nongkrong di tempat-tempat umum pada saat jam pelajaran. Hal ini juga dapat dijumpai dalam proses belajar siswa maupun dalam memenuhi tahap perkembangan siswa yang optimal, di mana tak sedikit anak yang hanya mengeluh ketika ditimpa penderitaan, merasa bahwa sekolah itu yang penting naik kelas meskipun dengan nilai yang pas-pasan dan lain-lain. ${ }^{5}$ Hal ini juga diperkuat dengan hasil wawancara dengan guru BK SMAN 1 Manyak Payed mengatakan bahwa sekolah yang penting lulus, sekolah adalah kegiatan untuk memperoleh uang saku, sekolah adalah ajang untuk mencari teman daripada menganggur di rumah, sekolah adalah kegiatan untuk menyenangkan orang tua serta agar mendapatkan pengakuan status sosial di lingkungannya. ${ }^{6}$

Guru bimbingan konseling bertujuan untuk membantu siswa mengembangkan diri secara optimal sesuai dengan tahap perkembangan dan predisposisi yang dimilikinya (seperti kemampuan dasar dan bakat-bakatnya), berbagai latar belakang yang ada (keluarga, pendidikan, status sosial ekonomi) serta sesuai dengan tuntutan positif lingkungannya. Adapun upaya guru BK dalam mengembangkan adversity quotient yang rendah siswa adalah dengan konseling individual dan bimbingan klasikal. Menurut Sofyan S. Willis konseling individual mempunyai makna spesifik dalam arti pertemuan konselor dengan klien secara individual, di mana terjadi hubungan konseling yang bernuansa rapport, dan konselor berupaya memberikan bantuan untuk pengembangan pribadi klien serta klien dapat mengantisipasi masalah-masalah yang dihadapinya. ${ }^{7}$ Sedangkan bimbingan klasikal merupakan layanan yang

5 Hasil observasi penulis di SMAN 1 Manyak Payed, pada tanggal 4 Agustus 2019 pukul 10.30 Wib.

6 Hasil wawancara dengan Ibu Khairi Wahyuna, S.Pd sebagai guru BK di SMAN 1 Manyak Payed, pada tanggal 4 Agustus 2019 pukul $10.30 \mathrm{Wib}$.

7 Sofyan S. Willis, Konseling Individual: Teori dan Praktek (Bandung : Alfabeta, 2004), h. 159. 
diberikan kepada semua siswa di dalam kelas. Hal ini menunjukkan bahwa dalam proses bimbingan sudah disusun secara baik dan siap untuk diberikan kepada siswa secara terjadwal, kegiatan ini berisikan informasi yang diberikan oleh seorang pembimbing kepada siswa secara kontak langsung guna membantu pertumbuhan anak dalam menentukan dan mengarahkan hidupnya. ${ }^{8}$

Berdasarkan latar belakang yang telah dijelaskan di atas, untuk itu peneliti tertarik untuk meneliti tentang “Upaya Guru BK dalam Mengembangkan Adversity Quotient Pada Siswa SMAN 1 Manyak Payed".

Untuk mendapat gambaran terhadap hasil penelitian yang telah dilakukan pada kesempatan ini dikaji beberapa hasil penelitian terdahulu sebagai berikut:

Pertama, skripsi dari Rizki Zahrotin M.U yang berjudul "Adversity Quotient Ada Siswa Broken Home Yang Berprestasi di MTsN 9 Bantul Yogyakarta". ${ }^{9}$ Tujuan penelitian untuk mengetahui dan mendeskripsikan tentang tipe adversity quotient siswa broken home yang berprestasi di MTsN 9 Bantul Yogyakarta.

Kedua, skripsi dari Marliya Ulva yang berjudul "Adversity Quotient Pada Guru Sekolah Luar Biasa di SLB-B Yayasan Pembinaan Anak Cacat (YPAC)

${ }^{8}$ Dewi Nur Fatimah, "Layanan Bimbingan Klasikal Dalam Meningkatkan Self Control Siswa SMP Negeri 5 Yogyakarta," HISBAH: Jurnal Bimbingan Konseling dan Dakwah Islam, Vol. 14, No. 1, Juni 2017, h. 28.

9 Rizki Zahrotin M.U, “Adversity Quotient Ada Siswa Broken Home Yang Berprestasi di MTsN 9 Bantul Yogyakarta," (Skripsi Program Studi Bimbingan Dan Konseling Islam Fakultas Dakwah Dan Komunikasi Universitas Islam Negeri Sunan Kalijaga Yogyakarta, 2018).
Palembang". ${ }^{10}$ Tujuan penelitian untuk mengetahui bagaimana adversity quotient pada guru sekolah luar biasa.

Ketiga, skripsi dari Laksmi Fivyan Warapsari yang berjudul "Adversity Quotient Pada Mahasiswa Berprestasi".11 Tujuan penelitian untuk memahami dan mendeskripsikan tentang bagaimana adversity quotient pada mahasiswa berprestasi.

Keempat, jurnal dari Hema G. \& Sanjay M. Gupta yang berjudul "Adversity Quotient for Prospective Higher Education".12 Tujuan penelitian untuk memahami Adversity Quotient (AQ) siswa yang akan masuk ke pendidikan tinggi. Sekolah menengah atas adalah tahap perpindahan dari sekolah ke pendidikan tinggi yang harus dihadapi mereka (siswa).

Kelima, jurnal dari Usha Parvathy \& Praseeda $\mathbf{M}$ yang berjudul "Relationship between Adversity Quotient and Academic Problems among Student Teachers"..13 Tujuan penelitian untuk mengetahui tingkat masalah akademik dan kecerdasan adversitas di kalangan guru siswa. Studi

10 Marliya Ulva, "Adversity Quotient Pada Guru Sekolah Luar Biasa di SLB-B Yayasan Pembinaan Anak Cacat (YPAC) Palembang," (Skripsi Program Studi Psikologi Islam Fakultas Ushuluddin Dan Pemikiran Islam Universitas Islam Negeri Raden Fatah Palembang, 2017).

11 Laksmi Fivyan Warapsari, "Adversity Quotient Pada Mahasiswa Berprestasi," (Skripsi Fakultas Psikologi Universitas Muhammadiyah Surakarta, 2015).

${ }^{12}$ Hema G. \& Sanjay M. Gupta, "Adversity Quotient for Prospective Higher Education," The International Journal of Indian Psychology Volume 2, Issue 3, April to June 2015.

13 Usha Parvathy \& Praseeda M, "Relationship between Adversity Quotient and Academic Problems among Student Teachers," IOSR Journal Of Humanities And Social Science (IOSR-JHSS) Volume 19, Issue 11, Ver. VII 
ini juga menganalisis hubungan antara adversity quotient dan masalah akademik di antara guru siswa.

Sedangkan tujuan penelitian ini, yaitu 1) untuk mengetahui gambaran adversity quotient pada siswa SMAN 1 Manyak Payed. 2) untuk mengetahui upaya guru BK dalam mengembangkan adversity quotient pada siswa SMAN 1 Manyak Payed.

\section{METODE}

Bagian metode berisi tentang rancangan penelitian, subjek penelitian, instrumen, prosedur pengumpulan data, dan analisis data yang dipaparkan dalam bentuk paragraf.

Penelitian ini menggunakan pendekatan deskriptif yaitu penelitian yang dimaksudkan untuk menyelidiki keadaan, kondisi atau hal lain-lain yang sudah disebutkan, yang hasilnya dipaparkan dalam bentuk laporan penelitian. ${ }^{14} \quad$ Penelitian deskriptif merupakan penelitian paling sederhana, dibandingkan dengan penelitian-penelitian yang lain karena dalam penelitian ini peneliti tidak melakukan apa-apa terhadap objek atau wilayah yang diteliti. Ini artinya bahwa dalam penelitian, peneliti tidak mengubah, menambah, atau mengadakan manipulasi terhadap objek atau wilayah penelitian. ${ }^{15}$

Penelitian ini bermaksud untuk mengungkap data dan informasi sebanyak mungkin tentang upaya guru BK dalam mengembangkan adversity quotient pada siswa SMAN 1 Manyak Payed. Penelitian ini tidak diarahkan pada kesimpulan salah-

14 Suharsimi Arikunto, Prosedur Penelitian: Suatu Pendekatan Praktik (Jakarta: Rineka Cipta, 2014), h. 3.

${ }^{15} \mathrm{Ibid}$. benar, tidak menguji suatu hipotesis diterima-ditolak, tetapi lebih ditekankan pada pengumpulan data untuk mendeskripsikan keadaan sesungguhnya yang terjadi di lapangan secara mendalam.

Dalam hal ini peneliti memperoleh sumber data primer melalui wawancara dengan informan seperti tujuh siswa yaitu yaitu Rima Triana, Dita Aprilia, Muhammad Lukkas, Randa Novi Safrida, Fina Fajri, Risna Maulina, Ansari dan seorang guru BK Khairi Wahyuna, S.Pd. Penentuan informan dalam penelitian ini dilakukan dengan cara purposive sampling. Purposive sampling menurut Djam'an Satori merupakan teknik pengambilan sampel yang ditentukan dengan menyesuaikan pada tujuan penelitian atau pertimbangan tertentu. ${ }^{16}$

Untuk memperoleh data yang sesuai dengan permasalahan yang di teliti, maka alat dan teknik pengumpulan data yang digunakan adalah observasi dan wawancara.

Model analisis data dalam penelitian ini mengikuti konsep yang diberikan Miles and Huberman. Miles and Hubermen mengungkapkan bahwa aktivitas dalam analisis data kualitatif dilakukan secara interaktif dan berlangsung secara terusmenerus sampai tuntas, sehingga datanya sudah jenuh. ${ }^{17}$ Adapun aktivitas dalam analisis data, yaitu:

\section{Reduksi data}

Data yang diperoleh dari laporan jumlahnya cukup banyak, untuk itu

16 Aan Komariah dan Djam'an Satori, Metode Penelitian Kualitatif (Bandung: Alfabeta, 2011), h. 6.

17 Sugiyono, Metode Penelitian Kuantitatif, Kualitatif dan RED (Bandung: Alfabeta, 2017), h. 246. 
maka perlu dicatat secara teliti dan rinci. Mereduksi data berarti merangkum, memilih hal-hal pokok, memfokuskan pada hal-hal yang penting, dicari tema dan polanya. ${ }^{18}$ Data yang telah direduksi akan memberikan gambaran yang lebih jelas, dan mempermudah peneliti untuk melakukan pengumpulan data selanjutnya, dan mencarinya bila diperlukan.

\section{Penyajian Data}

Penyajian data penelitian kualitatif bisa dilakukan dalam bentuk uraian singkat, bagan, hubungan antar kategori, dan sejenisnya. ${ }^{19}$ Penyajian data digunakan untuk lebih meningkatkan pemahaman kasus dan sebagai acuan mengambil tindakan berdasarkan pemahaman dan analisis sajian data. Dengan mendisplaykan data maka akan memudahkan untuk memahami apa yang terjadi, merencanakan kerja selanjutnya berdasarkan apa yang telah dipahami tersebut.

\section{Verifikasi atau penyimpulan Data}

Kesimpulan awal yang dikemukakan masih bersifat sementara, dan akan berubah bila ditemukan bukti-bukti yang kuat yang mendukung pada tahap berikutnya. Tetapi apabila kesimpulan yang dikemukakan pada tahap awal, didukung oleh bukti-bukti yang valid dan konsisten saat peneliti kembali kelapangan mengumpulkan data, maka kesimpulan yang dikemukakan merupakan kesimpulan yang kredibel. ${ }^{20}$

\footnotetext{
${ }^{18} \mathrm{Ibid}, \mathrm{h} .247$

${ }^{19} \mathrm{Ibid}, \mathrm{h} .249$.

${ }^{20} \mathrm{Ibid}, \mathrm{h} .252$.
}

\section{HASIL TEMUAN DAN PEMBAHASAN}

\section{A. Gambaran Adversity Quotient Pada Siswa SMAN 1 Manyak Payed}

Berdasarkan hasil penelitian yang peneliti lakukan di SMA Negeri 1 Manyak Payed, data diperoleh dari observasi dan hasil jawaban wawancara siswa dari rekomendasi oleh guru BK, di antaranya yaitu Rima Triana, Dita Aprilia, Muhammad Lukkas, Randa Novi Safrida, Fina Fajri, Risna Maulina, dan Ansari. Hasil wawancara di lapangan peneliti membaginya gambaran adversity quotient menjadi empat indikator, yaitu control (kendali), ownership (pengakuan), reach (ketercapaian), dan endurance (daya tahan).

\section{Control (kendali)}

Hasil analisis peneliti mengenai control (kendali) menunjukkan bahwa siswa-siswi belum mengendalikan tanggapan dirinya sendiri terhadap permasalahan yang sedang melanda. Hal ini berarti, siswasiswi tidak memiliki kendali yang besar dalam menghadapi persoalan dalam hidupnya. Mereka tidak mampu memperbaiki situasi yang menguntungkan secara positif. Mereka tidak mampu mengendalikan perasaannya dan tidak mampu memberikan tanggapan dengan lebih masuk akal. Mereka juga tidak mampu mempertimbangkan, mengelola, dan bahkan mengoptimalkan tanggapannya secara positif pada saat kesulitan melanda. Hal ini sesuai dengan pernyataan Stoltz mengenai dimensi control yaitu mempertanyakan seberapa banyak kendali yang kita rasakan terhadap suatu peristiwa yang menimbulkan kesulitan. Sehingga dengan control yang besar tidak menjadikan seseorang terjebak dalam ketidak-berdayaan terhadap kesulitan yang 
tengah dihadapi. ${ }^{21}$ Ketiga siswa tersebut di atas, belum dapat mengendalikan diri ketika sedang menghadapi suatu masalah seperti Rima yang tidak mampu untuk memotivasi diri, Ansari yang tidak mampu berpikir positif, dan Fina yang tidak mampu mengendalikan emosinya.

\section{Ownership (pengakuan)}

Hasil analisis peneliti mengenai ownership (pengakuan) menunjukkan bahwa siswa-siswi telah memiliki kemampuan yang baik dalam mengakui akibat-akibat kesulitan yang dialami. Siswa-siswi dengan dimensi ownership merupakan orang yang mau mengakui akibat dari suatu perbuatan apapun penyebabnya. Mereka tidak akan mempersalahkan orang lain dan mengelak dari tanggung jawab. Mereka akan belajar dari kesalahan-kesalahan dan cenderung mengakui akibat-akibat yang ditimbulkan tanpa mengingat penyebabnya. Rasa tanggungjawab inilah yang kemudian memaksa mereka untuk bertindak. Hal ini sesuai dengan pernyataan Stoltz mengenai dimensi ownership, Stoltz menyatakan tentang pengakuan terhadap akibat dari suatu permasalahan. Apabila dimensi origin menitikberatkan pada asal-usul suatu permasalahan, maka berbeda dengan dimensi ownership, dimensi ini lebih menitikberatkan pada pengakuan terhadap akibat dari suatu permasalahan. Mengakui akibat-akibat yang ditimbulkan oleh kesulitan mencerminkan tanggung jawab atas kesalahan atau kegagalan tersebut. ${ }^{22}$ Ketiga siswa tersebut di atas, telah dapat mengakui kesalahan dengan meminta maaf dan berjanji tidak akan mengulangi kesalahan yang sama lagi, meskipun

21 Stoltz, Adversity Quotient: Mengubah Hambatan, h. 141.

22 Ibid, h. 150. sumber kesalahannya berasal dari diri sendiri, teman, maupun dalam keluarga.

\section{Reach (ketercapaian)}

Hasil analisis peneliti mengenai reach (ketercapaian) menunjukkan bahwa sebagian sebagian siswa-siswi telah memiliki kemampuan dalam membatasi kesulitan agar tidak masuk ke dalam bidang kehidupan yang lain, seperti Rima Triana dan Ansari. Tetapi Fina Fajri memiliki kesulitan dalam membatasi kesulitan sehingga masuk ke dalam bidang kehidupan lain. Hal ini berarti sebagian dari siswa-siswi dapat membatasi jangkauan masalahnya pada satu masalah saja tanpa masuk pada segi kehidupan lainnya. Pada sebagian siswa-siswi lainnya yang memiliki skor reach rendah sangat besar kemungkinan bagi mereka untuk membuat kesulitan merembes pada segi kehidupannya yang lain. Mereka dapat menganggap masalah buruk sebagai bencana yang akan menyebar luas ke dalam bidang lainnya. Hal ini bisa sangat berbahaya karena akan menimbulkan kerusakan yang signifikan bila dibiarkan tidak terkendali. Hal ini sesuai dengan pernyataan Stoltz mengenai dimensi reach mempertanyakan sejauh manakah kesulitan akan menjangkau bagian-bagian lain dari kehidupan seseorang. Responrespon $A Q$ yang rendah akan membuat kesulitan memasuki segi-segi lain dari kehidupan seseorang. Semakin rendah skor reach (jangkauan) seseorang, semakin besar kemungkinannya orang tersebut menganggap peristiwa-peristiwa buruk sebagai bencana. Misalnya terdapat sebuah konflik bisa merusakkan seluruh hubungan yang sudah terjalin, suatu penilaian yang negatif akan menggangu proses belajar yang kemudian akan menimbulkan kepanikan secara finansial, sulit tidur, kepahitan, menjaga jarak 
dengan orang lain dan pengambilan keputusan yang buruk..$^{23}$ Dari ketiga siswa tersebut di atas, dua telah dapat kemampuan dalam membatasi kesulitan agar tidak masuk ke dalam kehidupan lainnya, yaitu Rima Triana dan Ansari, sedangkan yang belum yaitu Fina Fajri.

\section{Endurance (daya tahan)}

Hasil analisis peneliti mengenai endurance (daya tahan) menunjukkan bahwa siswa Rima Trian,Ansari dan Fina Fajri memiliki kemampuan yang baik dalam proses belajar tetapi memiliki kemampuan yang rendah dalam bertahan terhadap kesulitan. Hal ini berarti siswa memiliki kemungkinan menganggap kesulitan berlangsung lama, bahkan selama-lamanya. Hal tersebut tentu akan berbahaya jika dibiarkan tanpa diberi bantuan. Hal ini sesuai dengan pernyataan Stoltz mengenai dimensi endurance (daya tahan) mempertanyakan berapa lama seseorang menganggap kesulitan akan berlangsung. Semakin rendah skor endurance, semakin besar kemungkinan seseorang menganggap kesulitan dan/atau penyebab-penyebabnya akan berlangsung lama, bahkan selama-lamanya. ${ }^{24}$ Dari ketiga siswa yaitu Rima Triana, Ansari, dan Fina Fajri. Hanya Fina Fajri yang menganggap masalahnya memerlukan waktu yang lama dalam penyelesaiannya, namun ketiga nya belum mampu mengembangkan AQ yang di milikinya.

\section{B. Upaya Guru BK dalam Mengembangkan Adversity Quotient Pada Siswa SMAN 1 Manyak Payed}

Hasil analisis peneliti mengenai upaya guru BK dalam mengembangkan adversity quotient pada siswa SMAN 1 Manyak

\footnotetext{
${ }^{23}$ Ibid, h. 158

${ }^{24}$ Ibid, h. 162
}

Payed adalah dengan menggunakan bimbingan klasikal dan konseling individual, kedua teknik yang digunakan dalam melakukan proses mengatasi siswa yang mengalami kesulitan, di mana bimbingan klasikal yang digunakan terlebih dahulu, jika tidak ada perubahan, maka akan dilakukan konseling individual. Namun, konseling individual merupakan layanan yang sangat efektif digunakan untuk siswa yang mengalami AQ rendah apabila siswanya mengikuti semua arahan BK hasilnya siswa mendapatkan motivasi belajar dalam hidupnya, berusaha maksimal dan tidak mudah mengeluh namun ada juga proses konseling yang tidak mencapai hasil yang baik yaitu ketika siswa tidak mau bekerja sama dengan guru BK.

Selain kedua layanan yang diberikan oleh guru BK untuk mengembangkan AQ siswa, bentuk kerjasama guru BK dengan guru mapel dan orang tua siswa sangatlah penting dalam membantu proses konseling yang dilakukan, sebab guru BK dapat mengetahui pergaulan siswanya ketika berada di lingkungan sekolah melalui guru Mapel dan di luar sekolah melalui keterangan dari orang tuanya, selain itu juga orang tua akan dapat melanjutkan bimbingan yang telah diarahkan oleh guru BK sewaktu siswa berada di rumah.

\section{SIMPULAN}

Berdasarkan hasil penelitian dan pembahasan mengenai “Upaya Guru BK dalam Mengembangkan Adversity Quotient Pada Siswa SMAN 1 Manyak Payed", maka dapat disimpulkan bahwa:

1. Gambaran adversity quotient pada siswa SMAN 1 Manyak Payed dapat terlihat dari keempat dimensi, yaitu: 
a. Dimensi control (kendali), siswa belum dapat mengendalikan diri ketika sedang menghadapi suatu masalah.

b. Dimensi ownership (pengakuan), siswa dapat mengakui kesalahan yang dilakukannya dengan meminta maaf dan berjanji tidak akan mengulangi kesalahan yang sama lagi.

c. Dimensi reach (ketercapaian), sebagian siswa memiliki kemampuan dalam membatasi kesulitan agar tidak masuk ke dalam kehidupan lainnya dan sebagian siswa belum mampu membatasinya.

d. Dimensi endurance (daya tahan) siswa menganggap setiap masalah yang di hadapinya memerlukan waktu yang lama dalam menyelesaikannya.

2. Upaya guru BK dalam mengembangkan adversity quotient pada siswa SMAN 1 Manyak Payed berupa layanan bimbingan klasikal dan konseling individual, di mana bimbingan klasikal yang digunakan terlebih dahulu, jika tidak ada perubahan, maka akan dilakukan konseling individual. Selain dua layanan tersebut, bentuk kerjasama guru BK dengan guru mapel dan orang tua siswa merupakan faktor pendukung untuk proses menyelesaikan kesulitan siswa, dimana guru BK mendapatkan keterangan dari guru Mapel tentang siswa selama berada di lingkungan sekolah dan mendapat keterangan lainnya dari orang tua tentang sifat dan pergaulan anaknya ketika berada di rumah. Adapun kendala dalam mengembangkan AQ siswa adalah dari siswa sendiri yang tidak dapat mengikuti arahan/ bimbingan yang telah diberi, sehingga siswa tersebut tidak dapat mengatasi/ keluar dari kesulitan yang sedang dihadapi.

\section{DAFTAR PUSTAKA}

Arikunto, Suharsimi, (2014). Prosedur Penelitian: Suatu Pendekatan Praktik, Jakarta: Rineka Cipta, 2014.

Fatimah, Dewi Nur, (2017). “Layanan Bimbingan Klasikal Dalam Meningkatkan Self Control Siswa SMP Negeri 5 Yogyakarta," HISBAH: Jurnal Bimbingan Konseling dan Dakwah Islam, Vol. 14, No. 1.

G., Hema, \& Gupta, Sanjay M., (2015). "Adversity Quotient for Prospective Higher Education," The International Journal of Indian Psychology Volume 2, Issue 3.

Komariah, Aan, dan Satori, Djam'an, (2011). Metode Penelitian Kualitatif, Bandung: Alfabeta.

M.U, Rizki Zahrotin, (2018). "Adversity Quotient Ada Siswa Broken Home Yang Berprestasi di MTsN 9 Bantul Yogyakarta," Skripsi Program Studi Bimbingan Dan Konseling Islam Fakultas Dakwah Dan Komunikasi Universitas Islam Negeri Sunan Kalijaga Yogyakarta.

Parvathy, Usha, \& M, Praseeda, (2014). "Relationship between Adversity Quotient and Academic Problems among Student Teachers," IOSR Journal Of Humanities And Social Science (IOSR-JHSS) Volume 19, Issue 11, Ver. VII.

Stoltz, Paul G., (2000). Adversity Quotient: Mengubah Hambatan menjadi Peluang, 
Terjemahan oleh T, Hermaya, Jakarta:

Gramedia Widia Sarana Indonesia.

Stoltz, Paul G., (2003). Adversity Quotient in A Work: Mengatasi Kesulitan di Tempat Kerja, Terjemahan oleh Alexander Sindoro, Jakarta: Interaksara.

Sugiyono, (2017). Metode Penelitian Kuantitatif, Kualitatif dan R\&D, Bandung: Alfabeta.

Ulva, Marliya, (2017). “Adversity Quotient Pada Guru Sekolah Luar Biasa di SLBB Yayasan Pembinaan Anak Cacat (YPAC) Palembang," Skripsi Program Studi Psikologi Islam Fakultas Ushuluddin Dan Pemikiran Islam Universitas Islam Negeri Raden Fatah Palembang.

Warapsari, Laksmi Fivyan, (2015). "Adversity Quotient Pada Mahasiswa Berprestasi," Skripsi Fakultas Psikologi Universitas Muhammadiyah Surakarta.

Willis, Sofyan S., (2004). Konseling Individual: Teori dan Praktek, Bandung : Alfabeta. 